\title{
O MOODLE COMO SUPORTE PARA O ENSINO DO DESENHO GEOMÉTRICO
}

\section{MOODLE AS A SUPPORT FOR THE TEACHING OF GEOMETRIC DESIGN}

\author{
ZANARDI, Luciene de Maria de Souza ${ }^{1}$ \\ MATTOS, Francisco José Pinto
}

\section{RESUMO}

Este artigo apresenta um problema enfrentado pelo ensino da disciplina Desenho no Colégio Pedro II, tendo em vista que muitos alunos que ingressam na $1^{a}$ série do Ensino Médio, por meio de concurso, cursaram o Ensino Fundamental em escolas que não tem o Ensino de Desenho em suas grades. Esses alunos apresentam dificuldades na aprendizagem dos conteúdos da disciplina de Desenho durante o Ensino Médio, pois carecem de uma série de conteúdos que deveriam ter aprendido no Ensino Fundamental. Pensando nesse problema foi construído um produto educacional como forma de permitir que esses alunos tenham a possibilidade de acompanhar o desenvolvimento dos conteúdos de Desenho de modo similar aos demais colegas. O produto é composto por dois instrumentos integrados: o Ambiente Virtual de Aprendizagem - Moddle combinado com uma apostila impressa.

Palavras-chave: Geometria; Ensino; Desenho Geométrico; Ambiente Virtual de Aprendizagem; Moodle.

\section{ABSTRACT}

This article presents a problem faced by Pedro 2 Design Teaching team, given that many students that start high school had been studying in schools that did not have Design in their curriculum. These students present major difficulties when it comes to learning High school Design Curriculum because they lack a series of contents that should have been taught previously. To solve this problem an educational of product was built as a way to provide a similar opportunity for those students and help them in their new learning stage. The educational product has two components: the Virtual learning environment- moodle and a printed workbook.

KEYwORDS: Geometry; Teaching; Geometric draw; Virtual learning environment; Moodle.

\footnotetext{
${ }^{1}$ Professora de Desenho do Colégio Pedro II, Mestranda do Programa de Pós-Graduação em Práticas de Educação Básica do Colégio Pedro II e Especialista em Técnicas de Representação Gráfica - 2013 (UFRJ). e-mail: lucienezanardi@gmail.com

2 Professor do Mestrado Profissional em Práticas de Educação Básica do Colégio Pedro II e professor do Departamento de Matemática do CPII. Doutor em Ciências pela COPPE/UFRJ. e-mail: francisco.mattos@gmail.com
} 


\section{INTRODUÇÃO}

Este artigo é fruto de uma pesquisa desenvolvida no Metrado Profissional em Práticas de educação básica do Colégio Pedro II que teve como objetivo construir e viabilizar uma apostila integrada com o Ambiente Virtual de Aprendizagem - Moodle buscando suprir as possíveis carências de conteúdos da disciplina de Desenho Geométrico, por parte dos alunos ingressos na $1^{\text {a }}$ série do Ensino Médio, advindos por meio de concurso e que não tiveram Desenho Geométrico no Ensino Fundamental.

Analisando a situação podemos perceber através de pesquisas desenvolvidas como é o caso da tese de doutorado de Kopke (2016, p. 21) que aborda historicamente de acordo com as leis a desvalorização do ensino do Desenho Geométrico.

[...] a geometria vem sendo deixada de lado, é pouco estudada e muitas vezes relegada a segundo plano nas escolas. Contudo, é voz corrente entre os educadores e matemáticos de todo o mundo que ela deve ser encarada com prioridade nos programas escolares (D’AMBRÓSIO apud KOPKE, 2016, p. 23).

Dessa forma, muitas escolas no Rio de janeiro não possuem a Disciplina Desenho Geométrico em sua Grade Curricular no Ensino Fundamental. Logo, muitos alunos advindos por meio de concurso que ingressam na $1^{\text {a }}$ série do Ensino Médio possuem carência de conteúdos prévios para um bom desenvolvimento na disciplina de Desenho.

O Ensino do Desenho no Colégio Pedro II acontece da seguinte maneira: no Ensino Fundamental está voltado para o Desenho Geométrico (Geometria Plana),na qual o ensino se fundamenta na compreensão do espaço plano e suas questões métricas, assim, o estudo se baseia no plano bidimensional. Já no Ensino Médio a ênfase é o Desenho Projetivo (Geometria Descritiva) em que percebendo a tridimensionalidade dos objetos descrevemos a realidade com o uso de sistemas de projeções.

Logo, apesar de serem abordagens distintas da Geometria, os conteúdos estão interligados e são apresentados de maneira cumulativa. Assim, para um aluno do Ensino Médio construir a projeção de uma pirâmide reta de base hexagonal, ele deverá saber o que é a figura plana de seis lados: o hexágono, conteúdo do Ensino Fundamental.

\section{O Ensino do Desenho Projetivo e sua relação com o Desenho Geométrico}

O Ensino do Desenho no Colégio Pedro II apresenta algumas particularidades quando observamos os diferentes segmentos da Educação Básica. No EF podemos perceber que está voltado para o Desenho Geométrico (Geometria Plana), já no EM 
DOI: $10.12957 /$ e-mosaicos.2018.36988

para o Desenho Projetivo (Geometria Descritiva). Como podemos observar no fluxograma a seguir (Fig. 1):

Figura 1 - Organização da disciplina de Desenho no Colégio Pedro II.

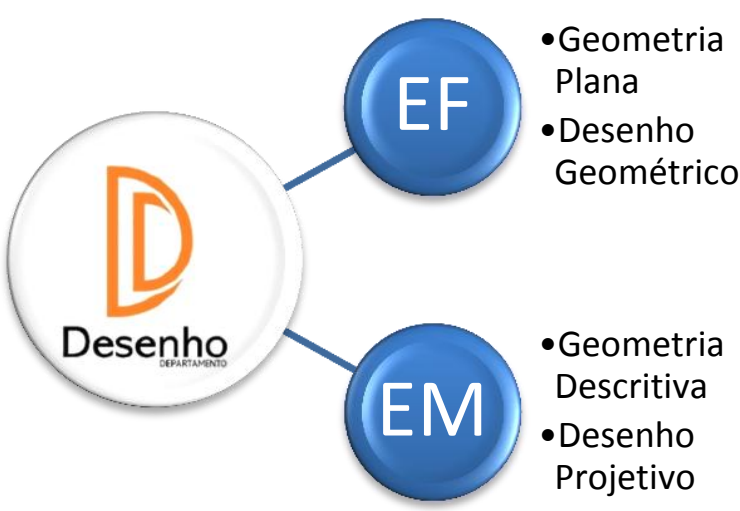

Fonte: Acervo dos autores.

Dessa forma, no EF os conteúdos estão voltados para o Desenho Geométrico que se desenvolve na superfície plana que possui duas dimensões, sendo elas, largura e altura. Vejamos alguns exemplos de construção de figuras planas (Fig. 2):

Figura 2 - Exemplo de construção de figuras planas (Circunferência de círculo, quadrado e hexágono regular).
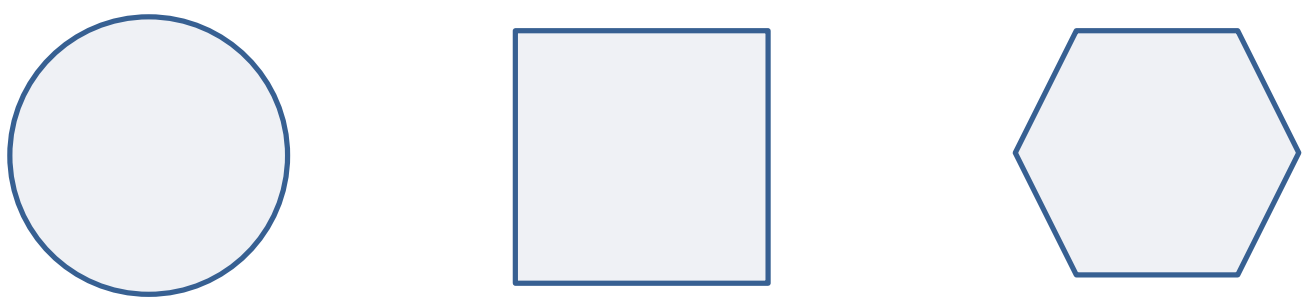

Fonte: Acervo dos autores.

Já no EM pensamos os objetos que são tridimensionais, ou seja, além de possuir largura e altura, possuem profundidade. Os objetos são projetados em um plano bidimensional que chamamos de plano de projeção. "Aqui há uma correspondência biunívoca entre o objeto (triângulo) e a imagem (desenho), isto é, a cada ponto da imagem corresponde um outro no objeto, e vice-versa." (MONTENEGRO, 1991, p.10)Como vemos no exemplo a seguir (Fig. 3): 
Figura 3 - Exemplo do Sistema ojeção Cônico

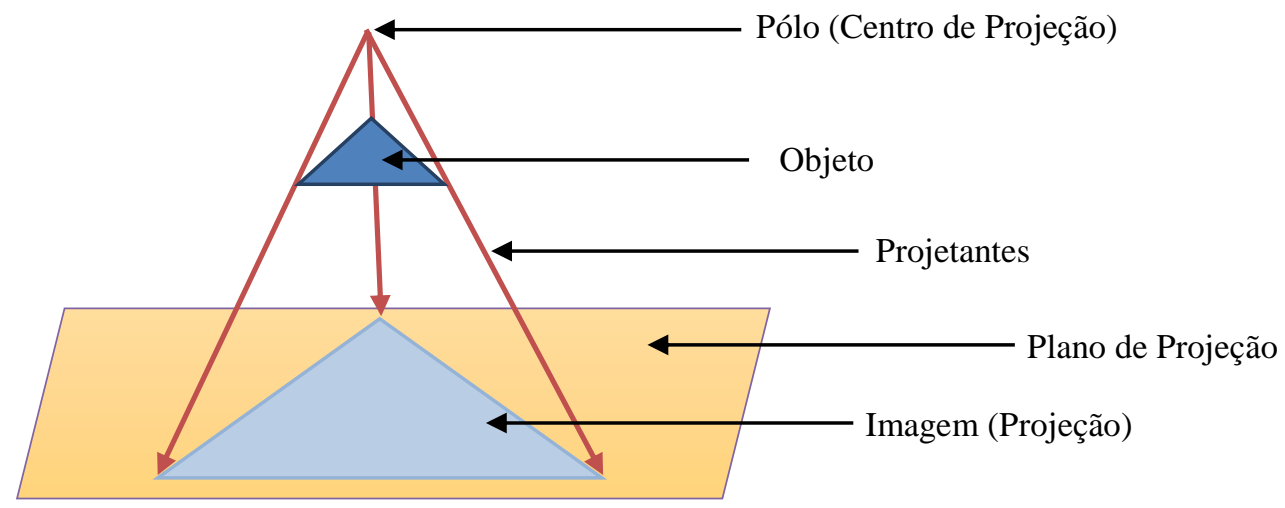

Fonte: Acervo dos autores.

A projeção ilustrada acima trata de um sistema de projeção cônico, "a denominação de 'cônico' para o sistema de representação em que o centro é próprio, isto é, está a uma distância finita do respectivo plano de projeção" (PINHEIRO, 1972, p. 2).

Assim, através dos sistemas de projeção podemos elaborar as chamadas perspectivas que atraem e enganam o nosso olhar, quando representamos o espaço tridimensional no plano.

No Renascimento italiano ${ }^{3}$ muitos artistas focaram seus estudos em representar a realidade que viam, dessa forma imaginavam que o quadro seria uma janela para o mundo, e assim utilizavam a Perspectiva Cônica. Pois:

Quando se pretende uma imagem expressiva, capaz de sugerir imediatamente o objeto, permitindo sua rápida compreensão, mesmo por parte do leigo, adota-se de preferência o sistema cônico, em virtude de sua identificação com o mecanismo visual (PINHEIRO, 1972, p.7).

O desenvolvimento da técnica de representação foi possível devido aos avanços nos estudos da geometria e da matemática que ocorreram durante a Idade Média.

Um bom exemplo da utilização da Perspectiva Cônica na Arte pode ser observada na obra do artista Rafael ${ }^{4}$ intitulada "A escola de Atenas" ${ }^{5}$ (Fig. 4).

\footnotetext{
${ }^{3}$ Movimento cultural e artístico desenvolvido na Europa entre 1300 a 1650.

${ }^{4}$ Rafael Sanzio (1483-1520)

${ }^{5}$ Afresco pintado no Palácio do Vaticano - Itália (1508 - 1511). Dimensões: 7,70m x 5,50m.
} 
Figura 4 - Afresco A escola de Atenas de Rafael

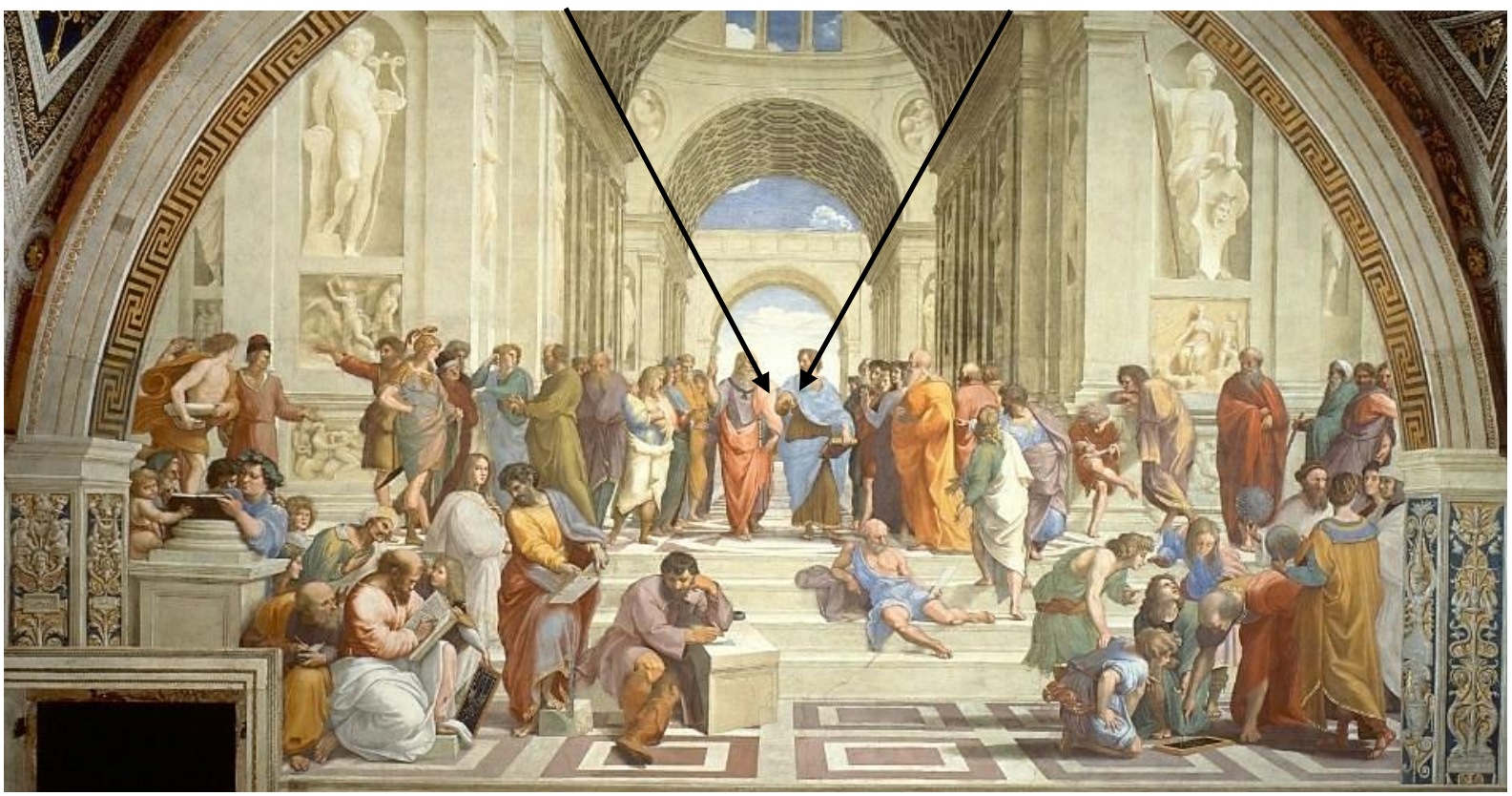

Fonte: Disponível em: https://digartdigmedia.wordpress.com/2016/12/08/revolucao-artisticae-o-uso-da-perspectiva/ . Acesso em 28/05/2018.

Nesta obra de Rafael podemos perceber ao centro do quadro os filósofos gregos Platão e Aristóteles e ao redor outros sábios e estudiosos. O nosso olhar caminha para o centro do quadro como indicado pelas setas em preto, destacando os filósofos que estão próximos ao ponto de fuga central visto que se trata de uma perspectiva cônica.

Assim através da perspectiva podemos também representar os sólidos geométricos como vemos abaixo (Fig. 5):

Figura 5 - Exemplo de sólidos geométricos representados em perspectiva (Cilindro reto, Hexaedro regular e Pirâmide reta de base hexagonal reqular).
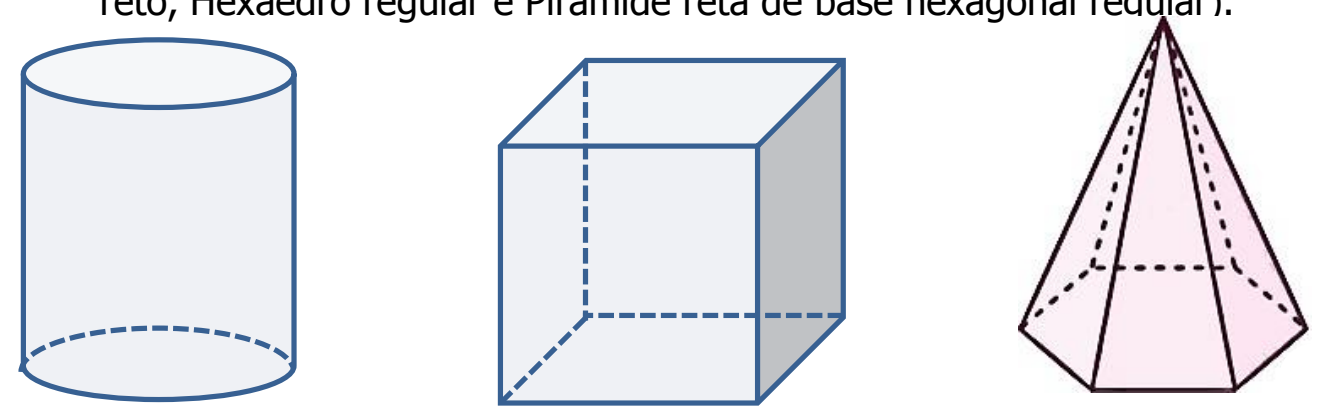

Fonte: Acervo dos autores. 
Se compararmos a Fig.2 com a Fig. 5 poderemos perceber a relação existente entre os conteúdos do EF (Desenho Geométrico) com os do EM (Desenho Projetivo) visto que uma das faces desses sólidos possuem o formato da figura plana representadas na Fig. 2.

Assim:

- A circunferência de círculo é a base do cilindro reto;

- O quadrado é a face do hexaedro regular;

- E o hexágono regular é a base da pirâmide reta de base hexagonal regular.

No EM o estudo do Desenho Projetivo abrange as noções básicas de projeção e os sistemas de projeção, observando suas possibilidades. Anteriormente falamos do sistema cônico de projeção que nos permite desenhar a perspectiva cônica.

Temos outro sistema denominado "cilíndrico" que ocorre quando se considera impróprio o centro de projeção. Este pode ser cilíndrico ortogonal ou oblíquo.

Quando, porém, prefere-se que a imagem seja uma fiel descrição da figura, independentemente de como se nos apresentaria à vista, isto é, uma imagem do objeto tal como ele é (e não como parece ser), adota-se o sistema cilíndrico- ortogonal. Por isso mesmo, um desenho por projeções ortogonais - isto é, um desenho descritivo, propriamente dito - exige uma interpretação que pressupõe 0 conhecimento das peculiaridades do método, ao contrário do que ocorre, em geral no desenho perspectivo (PINHEIRO, 1972, p. 7).

Dessa forma, uma parte considerável da grade curricular do EM se detém aos estudos sobre a Geometria Descritiva que foi desenvolvida por Gaspar Monge (17461818), e "é o mais importante método de representação por projeções ortogonais, não só pela simplicidade de sua concepção, como também pela ampla variedade de aplicações a que se presta" (PINHEIRO, 1972, p.8-9).

Assim, a GD trabalha com a dupla projeção relacionada em que os planos de projeção são perpendiculares um em relação ao outro. Temos a representação do sólido geométrico por suas projeções na épura ${ }^{6}$, como podemos perceber no exemplo a seguir (Fig. 6):

\footnotetext{
${ }^{6} \mathrm{~A}$ épura na GD é a sobreposição dos planos de projeção.
} 
Figura 6 - Representação de uma pirâmide reta de base hexagonal regular na geometria descritiva

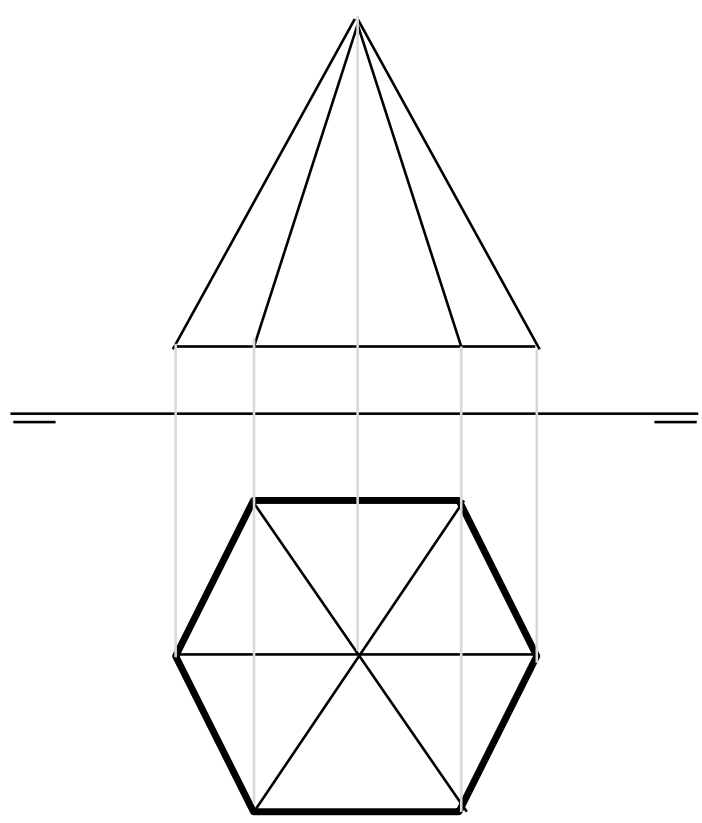

Fonte: Acervo dos autores.

O exemplo ilustra a importância do produto educacional desenvolvido. Como desdobramento desse processo podemos perceber uma série de relações entre os conteúdos do EF e EM. Por exemplo, as linhas de chamada que estão mais claras na Fig.6 são retas perpendiculares em relação a linha de terra que divide as duas projeções. $O$ conceito de retas paralelas e perpendiculares bem como sua construção com o par de esquadros estão entre os conteúdos ensinados no EF, assim, o aluno que teve contato com esse conteúdo terá um melhor entendimento e facilidade na construção da representação desta pirâmide.

Quando falamos do Ensino do Desenho é bom termos em mente que ele acontece de maneira cumulativa, ou seja, os conhecimentos aprendidos sempre serão solicitados, por exemplo, quando se busca a resolução de um problema geométrico ou se quer expressar utilizando a representação gráfica. Assim, "O desenho é a expressão gráfica da forma, e deste modo não é possível desenhar sem o conhecimento das formas a serem representadas" (CARVALHO, 2008, p. 11).

Acrescentando, Carvalho (2008, p. 11) fala que todas as coisas que vemos podem ser interpretadas como formas geométricas, e que por meio de estudo comparativo criam-se padrões e os conceitos geométricos. Dessa forma, o mundo que vemos se baseia nos princípios da geometria e a cada construção e invenção humana a geometria se faz presente, desde a imaginação que se desdobra em desenho de esboço até o desenho do projeto de fato, que com todas as formas e indicações de medidas pode ser construído pela indústria em larga escala. 


\section{AS TECNOLOGIAS DIGITAIS APLICADAS NO ENSINO}

A pesquisa do Mestrado profissional foi realizada no Campus São Cristóvão III onde os alunos concursados são alocados no turno da tarde. Em uma pesquisa documental realizada no ano de 2016 e em 2017, foram observados os históricos dos alunos ingressos por concurso nos respectivos anos, com o intuito de mensurar quantos alunos tiveram ou não a disciplina de Desenho Geométrico no Ensino Fundamental e temos assim o seguinte gráfico (Fig. 7):

Figura 7 - Alunos concursados de 2016 e 2017 que tiveram a disciplina de Desenho Geométrico

ALUNOS INGRESSOS NA 1a SÉRIE POR CONCURSO EM 2016

$\checkmark$ aluno teve a disciplina Desenho Geométrico no Ensino Fundamental?

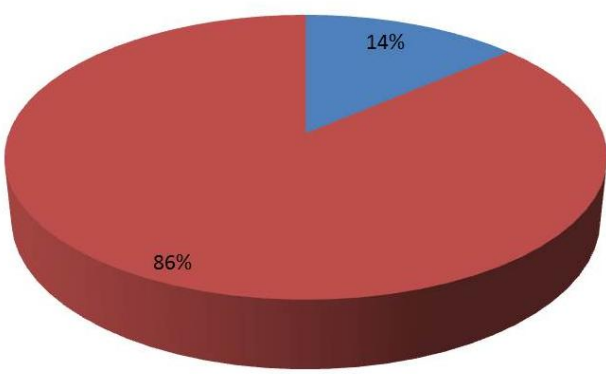

Fonte: Acervo dos autores.
ALUNOS INGRESSOS NA 1a SÉRIE POR CONCURSO EM 2017 $\checkmark$ aluno teve a disciplina Desenho Geométrico no Ensino Fundamental?

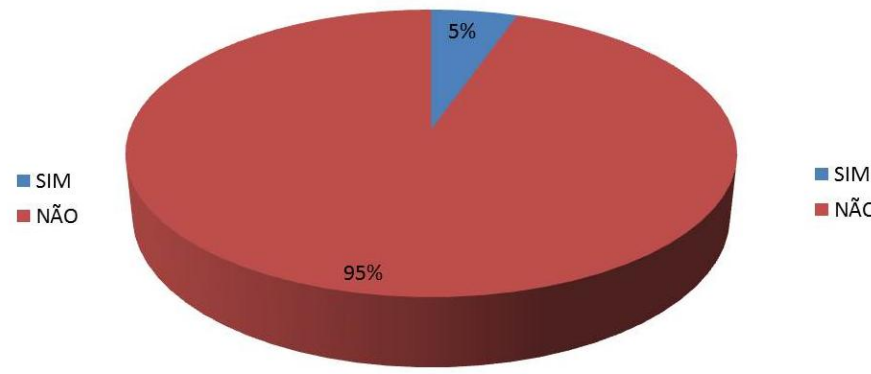

Ao observar a Fig. 7, percebemos que dos alunos que ingressaram por meio de concurso no ano de 2016 temos um percentual de $86 \%$ não tiveram contato com a disciplina de Desenho Geométrico e em 2017 esse percentual sobe para 95\% dos alunos. Assim, podemos entender a necessidade da execução de um projeto que possa ajudar de alguma forma esses alunos a compreenderem alguns conceitos fundamentais da disciplina.

Um ponto importante a ser ressaltado é que o ensino de Desenho Geométrico no Ensino Fundamental do CPII é ofertado nos quatro anos do segundo segmento. Sendo assim, até os alunos que tiveram Desenho Geométrico no Ensino Fundamental podem carecer de alguns conceitos, visto que nem todos possuem a disciplina nos quatros anos do segundo segmento do Ensino Fundamental. Como pôde ser observado na pesquisa realizada no histórico escolar desses alunos.

Se olharmos novamente a Fig. 7, em 2016 temos um percentual de 14\% que compõe os alunos oriundos de concurso que tiveram a disciplina de Desenho Geométrico no Ensino Fundamental, porém esse percentual se refere a apenas 19 alunos. E em 2017 temos um percentual de $5 \%$ de alunos que tiveram a disciplina, que representa apenas 5 alunos. 
DOI: $10.12957 /$ e-mosaicos.2018.36988

A pesquisa colheu informações por meio de questionários sobre 0 entendimento que os alunos tinham sobre alguns conceitos da disciplina de Desenho. Apresento uma questão para ilustrar a dificuldade de alguns alunos em reconhecer os instrumentos de Desenho.

Questão: Qual instrumento de Desenho Geométrico possibilita traçar retas paralelas // com facilidade?
a) Transferidor
b) Compasso
c) Régua
d) Lapiseira
e) Par de Esquadros

De acordo com as opções a que estaria de acordo seria a alternativa e) Par de Esquadros, que no CPII os alunos aprendem a utilizar desde $06^{\circ}$ ano do EF. Sabendo que foram colhidos 39 questionários, eis o gráfico das respostas (Fig. 8):

Figura 8 - Tabulação da questão 2 do questionário de conhecimentos prévios

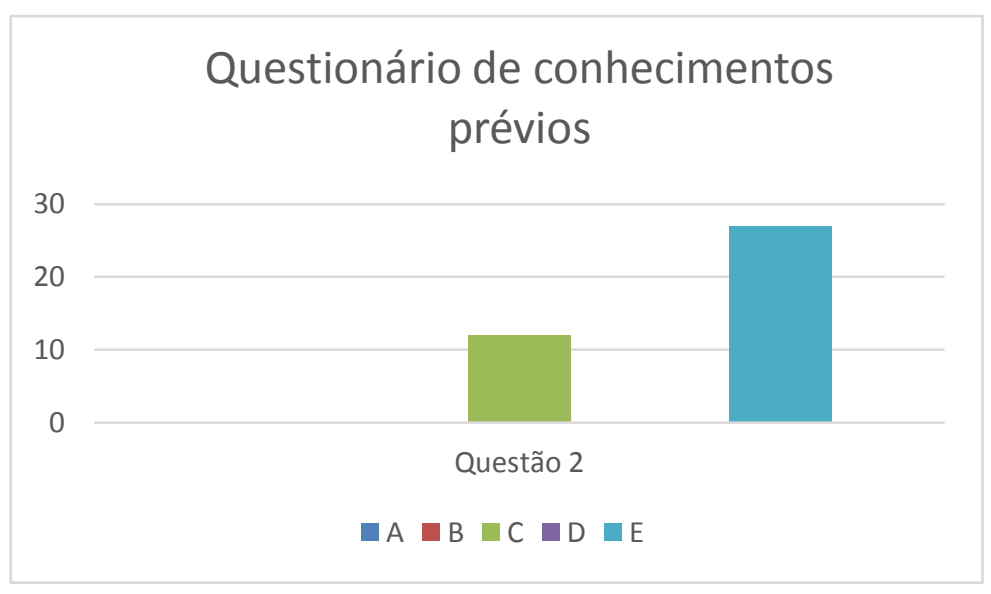

Fonte: Acervo dos autores.

Partindo dessas preocupações, a pesquisa teve como objetivo construir e viabilizar um produto educacional que possa colaborar na redução da carência de conhecimentos prévios favorecendo o aprendizado dos alunos ingressos por concurso na $1^{\text {a }}$ série do Ensino Médio. Principalmente, os que não tiveram contato com a disciplina de Desenho Geométrico no Ensino Fundamental. O produto educacional proposto busca viabilizar a igualdade de condições para os discentes aprenderem a disciplina de Desenho.

A ideia é propiciar um aprendizado dos conteúdos de Desenho de uma maneira mais dinâmica e motivadora, utilizando ferramentas digitais, como o 
e-Mosaicos - Revista Multidisciplinar de Ensino, Pesquisa, Extensão e Cultura do Instituto de Aplicação Fernando Rodrigues da Silveira (CAp-UERJ)

V. 7 - N. 15 - AGOSTO 2018 - ISSN: 2316-9303

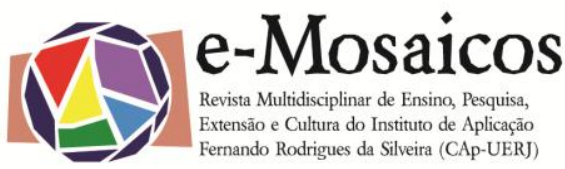

DOI: 10.12957/e-mosaicos.2018.36988

Ambiente Virtual de Aprendizagem (AVA) - o Moodle, oferecendo suporte a esses alunos.

Para isso, foi utilizado o Moodle combinado com uma apostila que depende do acesso ao ambiente para ser completada, propiciando aos alunos acesso aos conteúdos necessários para acompanharem o desenvolvimento de Desenho no Ensino Médio. Dessa forma, o método de estudo empregado se baseia no ensino à distância (EAD) integrando tecnologia (Plataforma Moodle) a um material tradicional (Apostila impressa). Essa integração é essencial, pois as ferramentas de EAD têm se mostrado como um facilitador do processo de ensino-aprendizagem devido aos recursos que podem ser utilizados, pois:

Essa modalidade de ensino possibilita a autoaprendizagem, através da mediação de recursos didáticos sistematicamente organizados, apresentados por meio de diferentes suportes de informação, podendo ser utilizados isoladamente ou combinados e veiculados pelos diversos meios de comunicação (COSTA; MOITA, 2011, p. 161).

A apostila foi disponibilizada por meio digital e impressa e contou com tópicos de assuntos considerados essenciais para que os alunos possam suprir a carência dos conteúdos de Desenho. Dessa forma, em cada tópico é abordado um conteúdo da disciplina com propostas de exercícios, indicações de acesso de vídeos, participações em fóruns, entre outras atividades na plataforma Moodle.

Nesse sentido, a relação da apostila com o Moodle, favorece para que os alunos possam construir seu aprendizado com autonomia, por meio da organização das informações, discussão dos conceitos e utilização dos instrumentos de Desenho Geométrico na execução de exercícios com a finalidade dos alunos desenvolverem a familiaridade com os mesmos.

O que se buscou foi viabilizar um produto educacional que pudesse auxiliar na redução das carências de conteúdos prévios da disciplina de Desenho por meio de uma aprendizagem mais autônoma e diferenciada e que por meio da interação aluno-professor e aluno-aluno desenvolvesse uma aprendizagem colaborativa, pela participação ativa nas atividades no Ambiente Virtual de Aprendizagem (AVA). 0 Moodle possibilita uma interação síncrona ou assíncrona, ou seja, a conversa entre os participantes ocorre ao mesmo tempo ou em momentos distintos, respectivamente. Como bem explicita Kenski (2012, p. 88):

A grande revolução no ensino não se dá apenas pelo uso mais intensivo do computador e da internet em sala de aula ou em atividades a distância. É preciso que se organize novas experiências pedagógicas em que as TICs possam ser usadas em processos cooperativos de aprendizagem, em que se valorizem o diálogo e a participação permanente de todos os envolvidos no processo. 
DOI: $10.12957 /$ e-mosaicos.2018.36988

Nesse sentido, temos o produto educacional: a apostila agregada ao Moodle, visando dar suporte para reduzir as ausências de determinados conteúdos. Cabe ressaltar que na construção do produto educacional o diálogo com os alunos foi fundamental, pois permitia a reflexão sobre o que foi alcançado e permitia pensar melhorias.

Dessa forma, a pesquisa seguiu como uma aproximação da metodologia da Pesquisa do Desenvolvimento que segundo Matta, Silva e Boaventura (2014, p. 30), propõe algumas orientações para a aplicação dessa abordagem metodológica, dividindo em quatro fases:

1- Análise do problema por investigadores, usuários e/o demais sujeitos envolvidos em colaboração;

2- Desenvolvimento da proposta de solução responsiva aos princípios de design, às técnicas de inovação e à colaboração de todos os envolvidos;

3- Ciclos interativos de aplicação e refinamento em práxis da solução;

4- Reflexão para produzir "Princípios de Design" e melhorar implementação da solução.

O produto educacional de que trata esse artigo pode ser adaptado e utilizado em outros contextos e situações.

A pesquisa seguiu com foco na questão da tecnologia do Moodle como suporte extraclasse, e no aprendizado a distância com tutoria online. E para pensar essas relações temos Kenski (2012) que trata da questão das tecnologias na educação, inclusive em seu livro Educação e tecnologias: $O$ novo ritmo de informação existe um capitulo que pensa os ambiente virtuais de aprendizagem.

Assim podemos perceber o quanto foi significativo utilizar o Moodle nesta pesquisa, visto que,

No ambiente virtual, a flexibilidade de navegação e as formas síncrona e assíncronas de comunicação oferecem aos estudantes a oportunidade de definirem seus próprios caminhos de acesso às informações desejadas, afastando-se de modelos massivos de ensino e garantindo aprendizagens personalizadas (KENSKI, 2012, p. 95).

Segundo a autora, os AVAs possuem três características: interatividade, hipertextualidade e conectividade, que auxiliam o processo de ensino aprendizagem a distância.

Quanto a isso o Professor Marco Silva $(2008$, p. 69) nos fala que a procura dos cursos online tem aumentado justamente por causa da flexibilidade, mobilidade e 


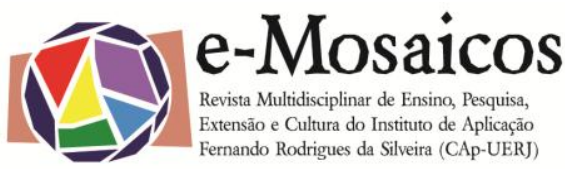

DOI: $10.12957 /$ e-mosaicos.2018.36988

atemporalidade que proporcionam. Assim, o aluno pode organizar seu estudo e inclusive fazê-lo em qualquer lugar, devido as novas tecnologias móveis.

A tecnologia aproxima quando há distância física, permitindo que o professor tutor, atenda um número maior de alunos que o faria em uma sala de aula convencional. Com os recursos do Moodle: links de vídeos, fóruns, chat, questionários, programas gráficos, materiais de leitura, entre outros podem favorecer significativamente para a aprendizagem dos conteúdos propostos. Pois,

A sala de aula se abre para o restante do mundo e busca novas parcerias e processos para ensinar e aprender. Comunicações entre alunos e professores se tornam comuns fora de sala de aula. Professores e alunos são contatados via e-mail em qualquer lugar, a qualquer hora. Dependendo do assunto, listas de discussões, fóruns, chats acontecem cada vez com mais frequência. As aulas se deslocam dos horários e espaços rígidos das salas presenciais e começam a criar vida de forma cada vez mais intensiva no ciberespaço (KENSKI, 2012, p.93).

A utilização do Moodle com uma apostila integrada visa orientar o estudo, proporcionando ao aluno a experiência com a tecnologia apoiada pelo palpável. Dessa forma, se agrega o manual e o tecnológico na busca do que cada um pode oferecer de melhor para orientar o aprendizado do aluno que precisa aprender os conteúdos de Desenho Geométrico que até então desconhecia ou pouco conhecia. Acrescido a isso, a internet e seu uso de maneira orientada pode promover 0 desenvolvimento do autoaprendizado, pois "o computador é a ferramenta auxiliar no processo de 'aprender a aprender'" (BEHRENS in MORAN, 2012, p. 99).

Outro fator de importância quando pensamos inserir a tecnologia no aprendizado é a questão da flexibilização do tempo e a possibilidade de adequação aos tempos de cada aluno aprender. Pois,

As atividades didáticas que contemplam a tecnologia da informação permitem ao aluno ir além da tarefa proposta, em seu ritmo próprio e estilo de aprendizagem. Neste novo processo educativo, o aluno dispõe de recursos para avançar, pausar, retroceder e rever o conhecimento. Esse processo permite fazer anotações e investigações pessoais, consultar materiais alternativos e complementares, bem como discutir com outros usuários ou com os próprios colegas suas produções (BEHRENS in MORAN, 2012, p. 103).

Nesse tempo que permite ao aluno fazer anotações e consultar outros materiais, temos a apostila que integrada com o Moodle pode ser um fator dinamizador e orientador da aprendizagem, além de dar a possibilidade aos alunos de testarem e desenvolverem suas habilidades com os instrumentos de Desenho 
DOI: $10.12957 /$ e-mosaicos.2018.36988

Geométrico na execução dos exercícios.

O Moodle tem como característica o ensino a distância e como nos diz Costa e Moita (2011, p.157-158) este ensino tem se mostrado uma importante ferramenta de democratização e disseminação dos conhecimentos, colaborando para preparar muitos profissionais para o mercado mundial. Além disso, a educação a distância favorece ao aprendiz o desenvolvimento da autoaprendizagem e devido à flexibilização do tempo oferece uma oportunidade de estudo para quem não poderia na modalidade presencial.

Dessa maneira, o produto educacional em questão ofereceu aos alunos que não tiveram a possibilidade de estudar os conteúdos de Desenho Geométrico no Ensino Fundamentaluma oportunidade de suprir essa carência como forma de diminuir as possíveis dificuldades na disciplina de Desenho durante o Ensino Médio.

\section{Produto educacional: Apostila e Moodle}

$O$ produto educacional desenvolvido é uma apostila integrada com o Ambiente Virtual de Aprendizagem - Moodle, que busca por meio de ícones no seu texto fazer referência para que o aluno acesse a plataforma. (Fig. 8) Ao acessar o Moodle espera-se que 0 aluno tenha mais informações e assim tenha contato com inúmeras formas de aprendizado, seja por meio de vídeos, textos, páginas da web, discussões em fóruns.

Figura 8 - Parte da apostila em que é solicitado ao aluno o acesso ao Moodle

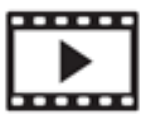

»Acesse o Moodle e veja o vídeo: Algumas dicas sobre os materiais

de Desenho.

Fonte: Acervo dos autores.

O Moodle é abreviação de Modular Object-OrientedDynamic Learning Environment, foi criado em 2001 por Martin Dougiamas que se preocupou em criar um ambiente virtual em que fosse possível troca de saberes de forma dinâmica. Dessa forma o objetivo do Moodle segundo Silva (p.101, 2015) é que a aprendizagem ocorra por meio da interação dando importância a construção e reconstrução do conhecimento de forma colaborativa. Nas imagens abaixo a aparência do Moodle (Fig. 9 e 10): 
e-Mosaicos - Revista Multidisciplinar de Ensino, Pesquisa, Extensão e Cultura do Instituto de Aplicação Fernando Rodrigues da Silveira (CAp-UERJ)

Figura 9 - Captura da tela realizada em 04/04/2018

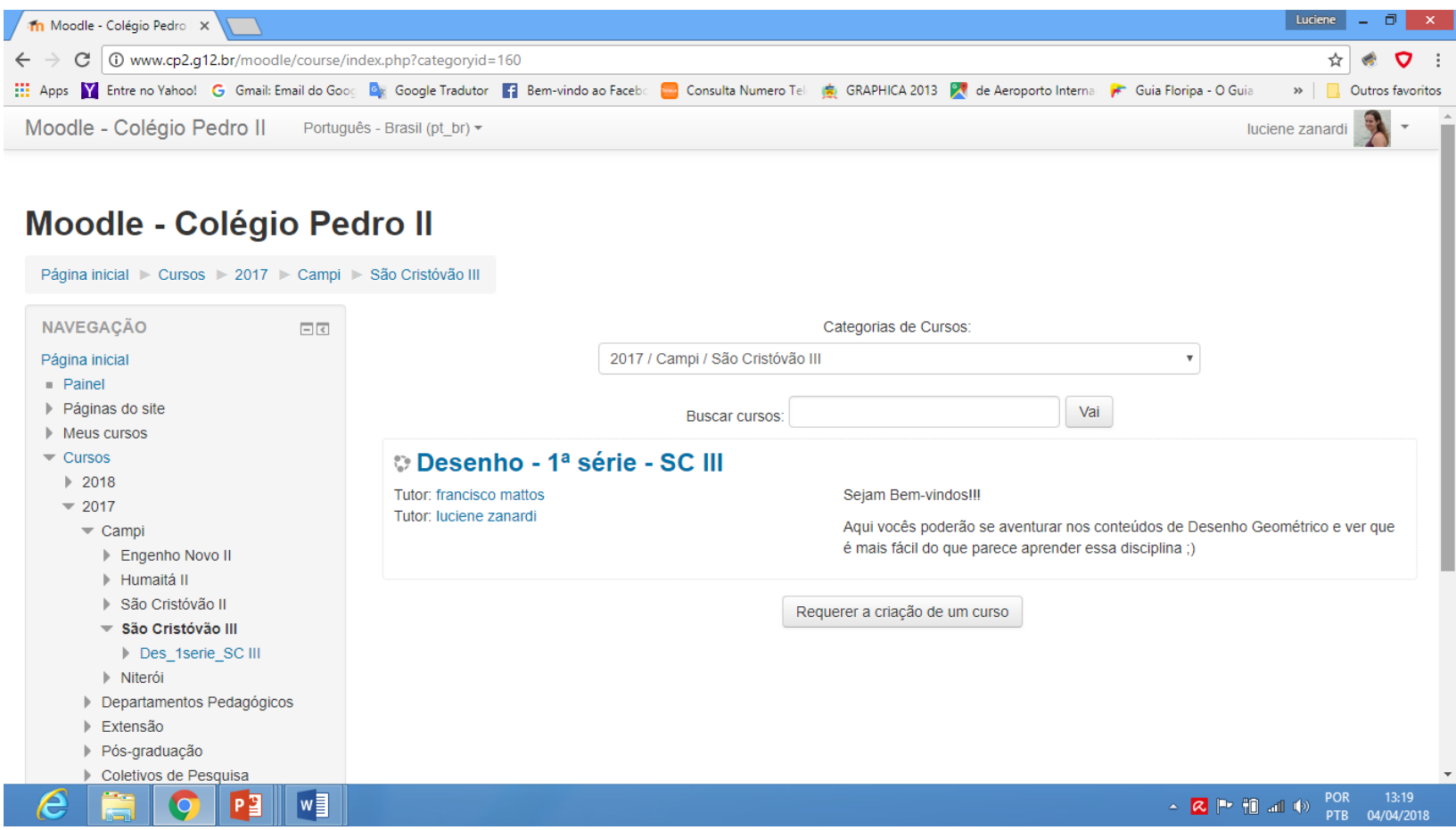

Fonte: Acervo dos autores.

Figura 10 - Captura da tela realizada em 04/04/2017

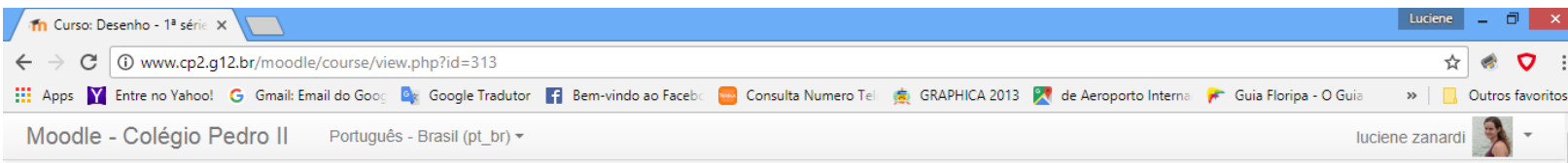

\section{Desenho - $1^{\text {a }}$ série - SC III}
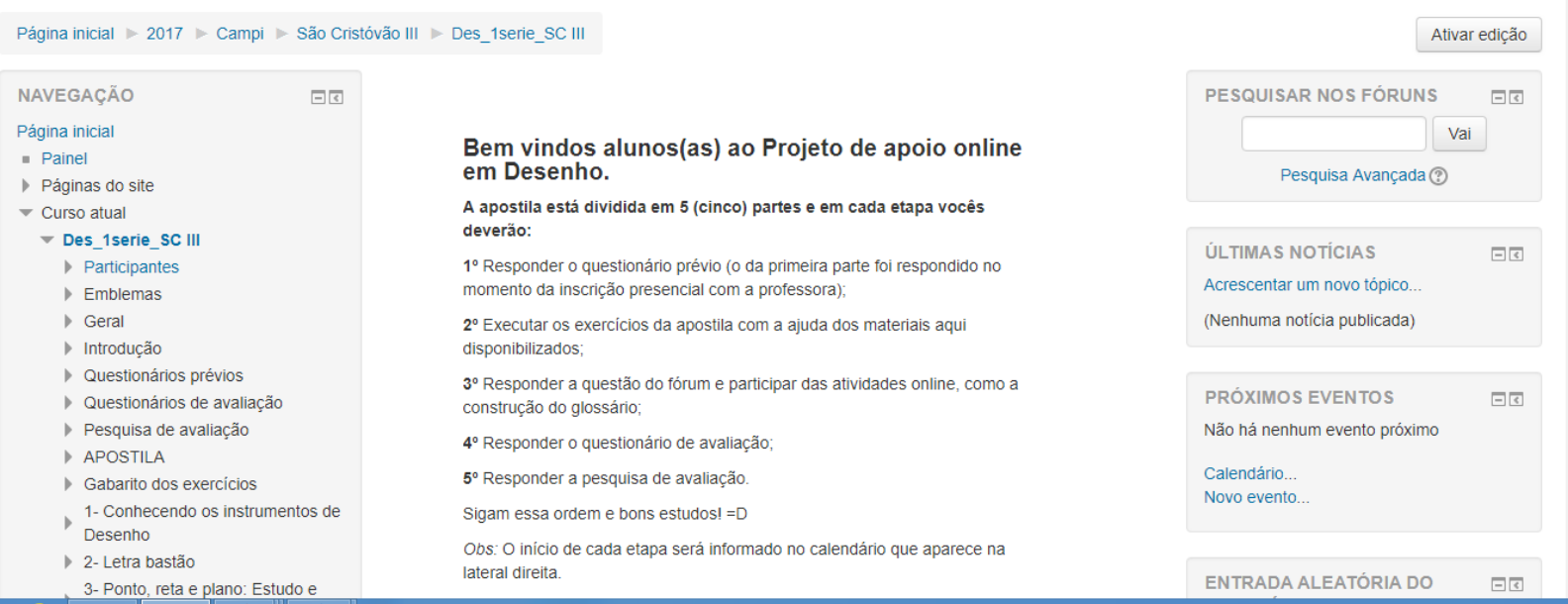

e. 0 P

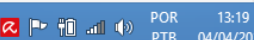

Fonte: Acervo dos autores. 
Como podemos perceber nas imagens de captura de telas (Fig. 9 e 10), a interface e o design da plataforma Moodle são bem claros e objetivos, sendo muito intuitiva. Os títulos e assuntos estão em letras escuras como o azul ou preto em sua maioria, sobre um fundo branco. Existe uma diferenciação entre os tamanhos e cor das letras de acordo com a importância de título para subtítulo.

No menu de navegação ao lado esquerdo temos setas de comando que permitem expandir e recolher, facilitando o acesso aos cursos, tópicos e seus conteúdos. Nas caixas de diálogo à direita temos o acesso às últimas novidades, fóruns, eventos, calendário entre outros.

Ao centro do site encontramos os assuntos principais em tópicos que se desdobram com seus conteúdos com a orientação de cima para baixo, facilitando o entendimento e a dinâmica do site, visto que se assemelha com a própria convenção de leitura e escrita ocidental.

A apostila que foi dividida de acordo com os conteúdos pertencentes ao Ensino Fundamental na Disciplina Desenho do Colégio Pedro II. Apresentamos a seguir o sumário da apostila:

1- Conhecendo os instrumentos de Desenho Geométrico

2- Caligrafia técnica

3- Ponto, reta e plano: Estudos e conceitos

4- Paralelas e perpendiculares: Utilizando os esquadros

5- Mediatriz e Bissetriz

6- Polígonos

7- Circunferência de Círculo

8- Retificação da circunferência de Círculo

9- Tangência e concordância

10 - Divisão de segmentos em partes proporcionais

A seleção dos conteúdos foi realizada por meio de comparação das apostilas relacionando os conteúdos que atualmente são aplicados no Ensino Fundamental e Ensino Médio do Colégio Pedro II com as apostilas de nivelamento ${ }^{7}$ que são oferecidas para os alunos que ingressam no E.M., pensando quais assuntos do Ensino Fundamental são prioritariamente necessários para que os alunos possam ter

\footnotetext{
7 São duas apostilas com alguns conteúdos de DG: uma que fala de forma bem resumida sobre as construções básicas (Ponto, linha e plano; Paralelas; Perpendiculares; Mediatrizes; Ângulos e Bissetrizes) e possui alguns exercícios para o aluno resolver, e a outra que também de forma resumida versa sobre os conteúdos: polígonos e circunferência de círculo e mostra alguns exercícios resolvidos.
} 


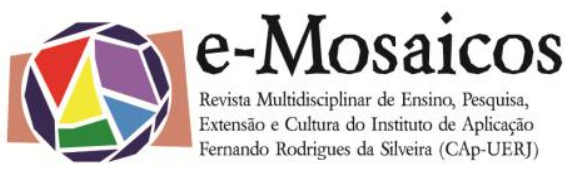

DOI: $10.12957 /$ e-mosaicos.2018.36988

bom desempenho no Ensino Médio. A partir dessa comparação, temos os conteúdos da apostila desse projeto, contando com assuntos essenciais para quem ainda não teve contato com a disciplina de Desenho Geométrico expressos de forma clara e enxuta, pois esse projeto é desenvolvido extraclasse, o que caracterizamos como uma extensão da sala de aula.

O produto educacional é classificado na categoria de desenvolvimento de material didático e instrucional, e foi construído durante todo o ano letivo de 2017, de forma a complementar o ensino de Desenho para esses alunos que ainda não tiveram contato com a disciplina. Tendo como objetivos: dinamizar o aprendizado dos conteúdos de Desenho Geométrico através da utilização da tecnologia do ambiente virtual de aprendizagem, possibilitando a criação de um espaço para troca e interação com os alunos e desenvolver habilidades gráficas e domínio dos instrumentos de desenho, ampliando o repertório visual.

O produto educacional visa orientar os alunos ingressos por concurso no entendimento dos conteúdos do ensino de Desenho Geométrico, unido o tradicional (apostila) com o tecnológico (AVA- Moodle). Dessa forma, como o aluno poderá expressar e desenvolver habilidades tanto com os instrumentos de desenho na apostila, quanto em um programa gráfico no computador online. $\mathrm{O}$ aluno possui 0 suporte tanto do resumo físico na apostila quanto das videoaulas presentes no Moodle.

Dessa forma, como Kenski (2012) nos diz o aluno poderá ter flexibilidade e autonomia no processo de ensino aprendizagem, contando com um leque de meios para o entendimento dos conteúdos de Desenho Geométrico.

Complementando Behrens in Moran (2012) nos fala sobre as atividades didáticas que trabalham com a tecnologia, expressando que essas permitem ao aluno exercer o auto aprendizado de acordo com seu ritmo. Por exemplo, o aluno poderá pausar a vídeo aula, anotar algo em sua apostila, ou até mesmo, realizar um exercício e voltar a assistir, bem como avançar e retroceder, quando achar necessidade.

\section{CONCLUSÃo}

O presente artigo revelou a possibilidade didático metodológica de se agregar - Moodle com uma apostila como forma de dar autonomia no aprendizado dos alunos. O produto educacional em questão buscou suprir a carência de conteúdos na disciplina de Desenho que ocorre em parte dos alunos que ingressam por meio de concurso no Ensino Médio do Colégio Pedro II.

O produto educacional em questão pode ser aplicado em outros contextos e disciplinas, como forma de suprir outras demandas, como por exemplo uma recuperação de conteúdos de determinada disciplina. Dessa forma, o Ensino a Distância pode vir a colaborar positivamente com as formas tradicionais de ensino. 


\section{REFERÊNCIAS}

CARVALHO, Benjamin de A. Desenho Geométrico. Rio de Janeiro: Imperial Novo Milênio, 2008.

COSTA, A. L. P. de O. MOITA, F. M. G. da S. C. Moodle no curso de ciências biológicas a distância: análise das contribuições no processo de ensino e aprendizagem. In: Tecnologias digitais na educação. Campina Grande: EDUEPB, 2011.

KENSKI, Vani Moreira. Educação e tecnologias: O novo ritmo da informação. - $8^{a}$ ed - Campinas, SP: Papirus, 2012.

KOPKE, Regina Coeli Moraes. Geometria, desenho, escola e transdisciplinaridade: abordagens passíveis para a educação. Tese (Doutorado em Educação). Rio de Janeiro: UFRJ, 2006.

MATTA, A.E.R.; SILVA F.P.S.; BOAVENTURA, E.M. Design-Basead Research ou pesquisa de desenvolvimento: metodologia para pesquisa aplicada de inovação em educação do século XXI. Revista da FAEEBA: Educação e Contemporaneidade. Salvador, v. 23, n. 42, p. 23-36, jul./dez. 2014.

MONTENEGRO, Gildo A. Geometria Descritiva. São Paulo: Blucher, 1991.

MOODLE. Disponível em <https://docs.moodle.org/all/es/P\%C3\%A1gina_Principal> (Acesso em 25 de maio de 2018)

MOODLE CPII. Disponível em <https://www.cp2.g12.br/moodle/login/index.php> (Acesso em 25 de maio de 2018)

MORAN, J. M. Novas tecnologias e mediação pedagógical José Manuel Moran, Marcos T. Masseto, Marilda Aparecida Behrens - 19a ed. - Campinas, SP: Papirus, 2012.

PINHEIRO, Virgilio Athayde. Noções de Geometria Descritiva. Vol 1 - 4 ed - Rio de Janeiro: Ao Livro Técnico, 1972.

SILVA, Marco. Cibercultura e educação: a comunicação na sala de aula presencial e online. Porto Alegre: Revista FAMECOS - n 37, Dez. 2008.

SILVA, Robson Santos da. Ambientes Virtuais e Multiplataformas Online em EAD. São Paulo: Novatec, 2015. 